\title{
MUDANÇAS TECNOLÓGICAS E SEU IMPACTO NO PROCESSO DE TRABALHO EM SAÚDE
}

\author{
TECHNOLOGICAL CHANGES AND THEIR IMPACT \\ ON THE WORK PROCESS IN THE AREA OF HEALTH
}

\author{
Marina Peduzzi 1
}

Resumo Objetiva-se aqui analisar as mudanças contemporâneas no mundo do trabalho e os seus efeitos ou impactos nos processo de trabalho em saúde. Trata-se de uma análise que toma como referencial teórico uma vertente dos estudos do trabalho em saúde desenvolvida no Brasil, no campo da saúde coletiva, que, partindo do pressuposto da consubstancialidade entre trabalho e necessidades sociais, vai aprofundar a investigação dos processos de trabalho e seus elementos constituintes, bem como da dimensão intersubjetiva e éticomoral da produção de serviços de saúde. Considerada, de um lado, a complexidade dos objetos de trabalho em saúde que requerem simultaneamente o aprofundamento vertical do conhecimento especializado e a sua integração e, de outro, a introdução de novos modelos organizacionais/gerenciais e a constante inovação e incorporação tecnológica, observam-se mudanças marcantes nos processo de trabalho, dentre as quais destacam-se: o caráter multiprofissional e interdisciplinar das práticas de saúde, o redimensionamento da autonomia profissional diante da necessidade de recomposição dos trabalhos especializados, e a necessidades de garantir maior e permanente qualificação profissional para o conjunto dos trabalhadores em saúde, tanto na dimensão técnica quanto na ético-política e comunicacional.

Palavras-chave trabalho em saúde; recursos humanos em saúde; ocupações em saúde.
Abstract Our objective here is to analyze the contemporary changes in the world of work and their effect - or their impact - on the work processes in the area of health. The theoretical reference for this analysis is a specific stream of studies on work developed in Brazil in the area of collective health. Starting from the assumption that work and social needs are consubstantial, the analysis deepens the investigation of the work processes and their constitutive elements, as well as of the inter-subjective and ethical-moral dimensions of the production of health services. Having considered, on the one hand, the complexity of the work objects in the area of health - that demand both a vertical increase in specialized knowledge and the horizontal integration of that knowledge -; and, on the other, the introduction of new organizational/managerial models and the constant presence of technological innovation and incorporation, we observed significant changes in the work processes, including, among others, the multi-professional and interdisciplinary character of health practices, the re-dimensioning of professional autonomy in the face of a need to recompose specialized work, and the need to provide all health workers with better and permanent professional qualifications, both in its technical and in its ethical-political and communicational dimensions.

Key words work in the area of health; Human Resources in health; occupations in health. 


\section{Introdução}

A reflexão sobre as transformações no processo de trabalho em saúde que iremos desenvolver toma como referencial teórico principal os estudos de Ricardo Bruno Mendes-Gonçalves (1979; 1992; 1994), sobretudo sua produção teórica sobre processo de trabalho em saúde, relações ciência/trabalho e saber operante, e, também, os estudos de Lilia Blima Schraiber $(1993 ; 1995)$ sobre autonomia profissional e sobre dimensão intersubjetiva do trabalho.

Consideraremos, também, as mudanças no mundo do trabalho na sociedade globalizada e o atual processo produtivo flexível, salientando o surgimento de um novo trabalhador polivalente e multifuncional, ou ainda, da especialização flexível do trabalhador coletivo. Iniciaremos considerando estes aspectos.

\section{As mudanças no "mundo do trabalho"}

Há um novo modo de operar o trabalho, configurado sobretudo ao longo dos anos 80, nas indústrias dos países de capitalismo avançado, que se estende em escala global. Estas mudanças no trabalho não atingiram igualmente todos os setores de produção e convivem com modalidades de trabalho anteriores. Porém, são lidas como tendências predominantes por acarretarem impacto significativo na produção de riqueza.

Esse novo modelo de organização do trabalho tem origem no quadro de recessão que se inicia na primeira metade dos anos 70, após mais de 20 anos de desenvolvimento e crescimento no pós-Segunda Guerra Mundial. A partir de então, as taxas de lucratividade são ameaçadas pela diminuição dos ganhos de produtividade, pela elitização do consumo e pelo aumento da competição intercapitalista mundial. O novo modelo de produção industrial que se esboça caracteriza-se pela grande importância do setor eletrônico, pela intensa aplicação da tecnologia digital de base microeletrônica e pelos progressos nos setores de química fina, dos novos materiais, de biotecnologia e de engenharia genética, beneficiados com os progressos da informática (Pires, 1996).

Vejamos o que assinalam alguns autores que vêm desenvolvendo estudos acerca das transformações tecnológicas e organizacionais e seus impactos no trabalho, sobretudo no setor industrial.

Antunes (1995) destaca os seguintes aspectos: a produção sustentada em um processo produtivo flexivel, uma vez que está conduzida pela demanda e voltada para atender as exigências mais individualizadas do mercado, no melhor tempo e qualidade; a flexibilização da produção e o alto ritmo de mudança técnica e a conseqüente especialização do trabalhador, que é tida como uma nova forma produtiva que articula, de um lado, um significativo 
desenvolvimento tecnológico e, de outro, uma desconcentração produtiva com base em empresas médias e pequenas, "artesanais"; a existência de uma combinação de diferentes processos produtivos, articulando o fordismo, da produção em massa, com processos flexíveis e "artesanais"; a necessidade de um trabalhador polivalente e multifuncional que se integra a uma equipe de trabalho, atuando frente a um complexo sistema de máquinas automatizadas; e as crescentes inovações e incorporações tecnológicas, levando à diminuição do tempo de trabalho necessário para produção e à ampliação das dimensões mais qualificadas e intelectuais do trabalho.

Esses aspectos, articulados na atual conjuntura político-econômica e cultural, provocam, no entender de Antunes (1995), o que ele denomina de processualidade contraditória na incorporação de trabalhadores, pois reduz o operariado industrial e fabril, porém aumenta o subproletariado; o trabalho precário, com contratos temporários, parciais, subcontratos e terceirizações; e o assalariamento no setor de serviços. Poderíamos ainda dizer que amplia a qualificação profissional necessária ao trabalho, mas também a desvalorização do trabalho e o desemprego.

Quanto a isto, é importante lembrar que, em torno de um núcleo de trabalhadores estáveis, apresentando um amplo leque de qualificações, flutua uma mão-de-obra periférica, de qualificações menores e mais limitadas, submetida ao acaso da conjuntura (Gorz apud Ianni, 1994).

Bernardes (1994), assim como Antunes, reafirma a centralidade da categoria trabalho, salientando a necessidade de reconceituá-la por intermédio de um novo paradigma de racionalidade ou sob uma "ótica transversal" que permita apreendê-la na sua multidimensionalidade. O autor afirma que a globalização e seu correlato, a regionalização, com a construção de blocos geoeconômicos, estão afetando os modos de atuação territorial e de gestão do espaço socioprodutivo da empresa, com uma remodelagem das estruturas verticalizadas e a configuração da empresa-rede, na qual a mobilização dos savoir-faire coletivos dos trabalhadores e os interesses de cooperação aumentam nos planos vertical e horizontal. A excelência do desempenho da empresa contemporânea está condicionada, em grande parte, pela capacidade de coordenação, coerência e cooperação entre os autores envolvidos.

Destacando a crescente automação, os novos padrões de gestão do trabalho, que estariam sendo definidos pela reintegração da execução e da concepção, pela polivalência dos trabalhadores convocados a realizar tarefas diversificadas e multiqualificadas, com maximização dos conhecimentos e domínio sobre o conjunto do processo global, e destacando, também, a diminuição das estruturas hierárquicas e administrativas frente ao processo de trabalho flexível, Bernardes (1994) coloca a emergência de uma nova divisão do trabalho, menos pronunciada do que no taylorismo e no fordismo e com maior integração de funções. 
A flexibilização funcional que atenua os níveis de divisão de trabalho, segundo o autor, seria de dois tipos: agregação de funções para cada trabalhador, em que um único homem controla um conjunto de máquinas; e rotação por diferentes tarefas, como na experiência do trabalho em equipes, que se responsabilizam pela seqüência inteira de uma etapa produtiva, com o enriquecimento dos cargos que arcam com todas as funções coletivamente.

Ianni (1994) também chama a atenção para o surgimento de novas relações no interior da divisão do trabalho, pois as tecnologias microeletrônicas, a automação e a robótica intensificam as possibilidades de racionalização do processo produtivo alterando as condições de articulação entre as forças produtivas, bem como entre trabalho intelectual e manual. Ianni exemplifica dizendo que o operário, o técnico e o engenheiro são postos em novas relações recíprocas e contínuas, diversificadas e inovadoras, no âmbito do processo produtivo.

Como já salientamos, há uma tendência à maior qualificação dos trabalhadores, pois o produto depende cada vez menos das operações diretas do trabalhador individual, e cada vez mais de trabalhos coletivos articulados e da relação inteligente homem/máquina, na qual têm papel decisivo, para garantir maior produtividade, a iniciativa, a responsabilidade e a antecipação para detecção de possíveis falhas técnicas. A iniciativa é importante também no sentido de propiciar o engajamento do trabalhador na inovação tecnológica, pois, em parcelas significativas da produção econômica (microeletrônica, computadores, química fina, telecomunicações e biotecnologia), produzir avanços tecnológicos é o estágio primordial do ciclo produtivo, bem como a inovação é o principal produto ou serviço que vendem (Bernardes, 1994). Assim, ocorre uma crescente valorização da capacidade de inovação e da inventividade dos trabalhadores.

Esse novo trabalhador, no qual convergem, em graus variados, a concepção e a execução do trabalho, em um novo ambiente tecnológico e organizacional, necessita de uma qualificação que inclua múltiplos aspectos: habilidades cognitivas, de abstração e análise simbólica, comunicacionais; de inter-relação com clientes e demais trabalhadores; iniciativa e criatividade; capacidade de trabalhar cooperativamente em grupo e para a formação mútua no próprio local de trabalho; competência para avaliar o produto de seu trabalho e tomar medidas para melhorar sua qualidade; e domínio de técnicas de planejamento e organização do trabalho (Bernardes, 1994 e Gitahy, 1994). Portanto, necessita de uma sólida formação básica, além da capacitação profissional.

Bernardes (1994) destaca o lugar central da comunicação e das inter-relações nesse novo modo de produzir o trabalho, tanto pela sua complexidade como pela necessidade de cooperação e, portanto, da identificação e superação dos obstáculos à cooperação. 
É interessante observar que essa "revolução" tecnológica estende-se ao conjunto das atividades que envolvem informação, englobando o conjunto das atividades de serviço, onde encontra-se o setor saúde.

No centro do debate sobre as mudanças no mundo do trabalho estão o questionamento da categoria trabalho e sua potencialidade explicativa ou como fonte de compreensão da realidade. A título de esclarecimento, concordamos com a necessidade de considerar as novas características da produção e de re-situar o trabalho no universo da práxis humana, questionando sua centralidade na conformação da sociedade. Porém, a nosso ver, a reestruturação do trabalho não implica desconsiderar a categoria trabalho como recurso teórico e analítico que permite a apreensão de certos aspectos da realidade, realidade esta que não reduz à dimensão trabalho ou a qualquer outra dimensão possível, ao curioso olhar humano.

Essa ressalva cabe em especial ao trabalho em saúde, tal como o vemos, talvez até pelo fato de que, contraditoriamente, a categoria trabalho nunca aplicou-se completamente à saúde. A peculiaridade de ação intrínseca à dimensão trabalho fez com que o uso desta categoria iluminasse, por analogia, o trabalho social típico do campo da saúde.

Parece-nos interessante resgatar as contribuições de Offe (1989) no questionamento da sociedade do trabalho. $\mathrm{O}$ autor afirma que o trabalho constituía o ponto de partida empírico para as construções teóricas dos sociólogos clássicos (Durkheim, Marx e Weber), porém questiona sua continuidade como categoria macrossociológica fundamental ao analisar a produção contemporânea das ciências sociais, na Alemanha. O autor questiona a centralidade da sociedade do trabalho, apresentando três indícios de seu deslocamento para outras esferas da vida humana, que são apresentadas como três conjuntos de questões: a primeira refere-se à persistência de qualquer relevância sensível do trabalho remunerado dependente, como tal, na percepção dos interesses sociais, na autoconsciência, no comportamento organizacional e político dos trabalhadores, dada a crescente diferenciação interna do trabalho, sobretudo a crescente heterogeneidade entre produção de bens e produção de serviços; a segunda refere-se à validade e à centralidade do conceito do trabalho para aqueles que trabalham, pois a descontinuidade da biografia do trabalho e a redução do tempo de trabalho no tempo de vida tendem a tornar o trabalho um assunto "entre outros", relativizando sua função como ponto de referência para a construção da identidade pessoal e social; a terceira indagação, decorrente de complementar às duas anteriores, diz respeito à necessidade de um sistema de coordenadas conceituais, com o qual seria possível cartografar as esferas da realidade social não plenamente determinadas pelo âmbito do trabalho e da produção, buscar as estruturas, os campos de ação e de relações de sentido além da esfera do trabalho. Quanto à última questão, o autor destaca as contribuições de Jürgen Habermas (2001). 
Offe (1989) argumenta que, diante da multiplicidade empírica das situações de trabalho, não mais se pode falar de uma unidade fundamental, de um único tipo de racionalidade organizando e regendo todo trabalho. Como já citado, Offe analisa a existência de processos multidimensionais de diferenciação interna do trabalho, distinguindo o trabalho assalariado industrial do trabalho reflexivo em serviços.

O autor define serviços como atividades que atuam na mediação do processo produtivo buscando dar conta da questão da "normalização", ou seja, atividades de prevenção, absorção e assimilação de riscos e desvios da normalidade, e defende que a produção em serviços tem uma racionalidade técnica própria e distinta da produção de bens, apesar de também exteriorizarse como trabalho assalariado no bojo de organizações privadas ou públicas. Esta diferenciação acontece por duas características do trabalho em serviços: a falta de homogeneidade, a descontinuidade e a incerteza temporal, social e material dos "casos" que não permite normatizar uma função técnica de produção a ser adotada como critério de controle de execução do trabalho; e a não disposição de um claro e inquestionável critério de economicidade, a partir do qual se possam derivar estrategicamente o tipo, o volume, o local e o momento de oferta do serviço, resultando o trabalho, muitas vezes, em utilidades concretas e não em rendimento monetário.

As contribuições de Offe sobre as peculiaridades do trabalho em serviços, assim como os estudos de autores brasileiros sobre o trabalho em saúde, desde a ótica "interna" do processo de trabalho, exploram dimensões mais conjunturais e microscópicas do trabalho. Poderíamos dizer que representam um deslocamento por referência à abordagem mais clássica da categoria trabalho que coloca a reprodução material do mundo e da vida como fundadora da sociedade humana.

\section{Características do trabalho em saúde}

Mendes-Gonçalves (1979, 1992, 1994) adota a categoria trabalho como nuclear para a apreensão e compreensão das práticas de saúde, partindo do pressuposto da consubstancialidade das práticas técnicas com a sociedade e da ciência com a sociedade, ou seja, tomando tanto a dimensão do trabalho quanto a dimensão do conhecimento científico como intrinsecamente históricas e com compromissos sociais.

Nos seus estudos sobre processo de trabalho, o autor investiga teórica e conceitualmente a aplicação da teoria marxista do trabalho ao campo da saúde e a conformação dos seus elementos constituintes - objetos, instrumentos materiais/intelectuais (saberes) e a atividade humana. E, dado seu olhar também epistemológico, avança na distinção e relação do mundo do trabalho e 
do mundo da ciência, introduzindo a categoria saber operante (Mendes-Gonçalves, 1994).

Desde a elaboração da dissertação de mestrado, Mendes-Gonçalves salienta que a medicina estruturou-se com base nas ciências biológicas, ditas ciências básicas (anatomia, patologia e fisiologia), porém não se confunde com estas ciências e sim configura-se como um trabalho cujo objeto é o corpo anatomo-fisiológico (Mendes-Gonçalves, 1979, 1994). Isto não significa que a identificação da prática médica a uma prática em si mesma científica seja um erro ou uma ilusão, mas sim um aspecto constituinte desta prática que, sendo contemporânea e partícipe da construção da racionalidade científica moderna, adquire, por sua representação social como prática científica, o poder de legislar e julgar sobre a saúde e a doença (Mendes-Gonçalves, 1994).

Antes de continuarmos sobre o trabalho em saúde, chamamos mais uma vez a atenção para a distinção entre ciência e saber. Foucault (1995) refere-se ao saber como o conjunto de elementos formados de maneira regular por uma prática discursiva e que são indispensáveis à constituição de uma ciência, apesar de não se destinar necessariamente a lhe dar lugar; o domínio constituído pelos diferentes objetos que adquirirão ou não um estatuto científico; o espaço em que o sujeito pode tomar posição para falar dos objetos de que se ocupa em seu discurso; e ainda o campo de coordenação e subordinação dos enunciados, em que os conceitos aparecem, se definem, são aplicados e se transformam.

Na linha de diferenciação entre saber e ciência, Foucault acrescenta que, no interior de um dado campo de saber encontram-se inscritas ciências, que, em uma análise arqueológica, podem ser apreendidas em diferentes limiares de epistemologização, de cientificidade e de formalização.

O campo da medicina, fundado cientificamente, constrói duas modalidades de saber - o clínico e o epidemiológico. Estes saberes permitem a apreensão do objeto do trabalho médico, pois o saber é que recorta, da realidade, aspectos que se constituem objetos de intervenção. O saber configura, junto com os demais instrumentos do trabalho, possibilidades de intervenção e, mesmo sem as dimensões materiais de equipamentos, tem uma dimensão tecnológica e/ou operante.

A categoria saber operante, então, permite apreender o agente do trabalho como mediador, que estabelece relações entre os conhecimentos científicos, os saberes e as dimensões ético-políticas de ambos, e, na prática cotidiana do trabalho, utiliza o saber operante mediando a conexão entre o objeto, os instrumentos e a atividade do trabalho (Mendes-Gonçalves, 1994). O saber operante, portanto, significa conhecer internamente como se realiza cada ação do trabalho e conhecer o projeto do conjunto de ações realizadas. Note-se que no trabalho há o concurso de diversos saberes, lembrando que os saberes são campos de inscrição de ciências e de outros conhecimentos. 
Outra categoria que Mendes-Gonçalves trabalhou com afinco e é particularmente importante no presente caso, uma vez que tratamos das mudanças no processo de trabalho, é a tecnologia. Segundo o autor, o conceito tecnologia não se resume ao conjunto de instrumentos materiais do trabalho, concebidos usualmente como instrumental dado a priori e fundamentado cientificamente, mas sim ao conjunto de saberes e instrumentos que expressa, nos processos de produção de serviços, a rede de relações sociais em que seus agentes articulam sua prática em uma totalidade social (Mendes-Gonçalves, 1994), ou seja, a tecnologia é concebida como uma modalidade de organização do trabalho e como um saber.

Mendes-Gonçalves retoma o sentido etimológico do termo tecnologia que se refere aos nexos técnicos estabelecidos no interior do processo de trabalho, ou seja, aos nexos entre a atividade e o objeto de trabalho, através dos instrumentos. E, salientando a abrangência da tecnologia para além dos instrumentos materiais, o autor lembra as controvérsias sempre geradas pela poupança de força de trabalho e pela redução de emprego que a incorporação de novas tecnologias pode acarretar.

Os estudos de Schraiber (1993; 1995) sobre trabalho em saúde partem dos mesmos pressupostos apontados no início do texto, porém, dentre os elementos constituintes do processo de trabalho, destacam o agente/sujeito do trabalho como questão nuclear de investigação e enfatizam a dimensão intersubjetiva e ético-moral dos processos de produção de serviços.

Schraiber (1993) analisa o processo de transição do modelo de medicina liberal para o da medicina tecnológica e seus reflexos na autonomia profissional do médico, tendo a medicina liberal ocupado o período histórico do século XIX dos anos 40 a 60, respectivamente, nos países desenvolvidos, como os Estados Unidos, e nos de desenvolvimento capitalista mais tardio, como o Brasil, e sendo a medicina tecnológica o modelo contemporâneo de trabalho especializado e com forte incorporação instrumental.

Quanto à autonomia profissional do médico, a autora destaca um tensionamento entre o ideal de profissão autônoma, com pleno controle sobre o trabalho, e as restrições à autonomia colocadas pelas políticas públicas e pelas políticas empresariais. Schraiber (1993) analisa, também, as estratégias de preservação da autonomia médica, enquanto estratégias de preservação do monopólio da prática médica, essencialmente na dimensão do saber operante.

Em estudos posteriores, o conceito de autonomia profissional é discutido por referência ao trabalho coletivo, ou seja, realizado por um conjunto diversificado de profissionais (Schraiber e Peduzzi, 1993), assim como é desdobrado em três categorias: autonomia mercantil, técnica e hierárquica (Ribeiro e Schraiber, 1994; Schraiber, 1995).

Na perspectiva até agora assinalada, trabalho em saúde é um processo de transformação no qual o agente, através de suas ações, faz a finalidade 
social do próprio trabalho realizar-se. As ações são realizadas com base em um saber operante e em um dado modelo tecnológico, traduzindo projetos coletivos e individuais, pois o sujeito do trabalho, para além de portador de projetos e valores coletivos e/ou institucionais, tem projetos próprios que lhe permitem construir estratégias de adesão ou recusa aos primeiros.

Não pretendemos nos alongar nas considerações acerca dos estudos sobre o trabalho em saúde, uma vez que há disponível uma interessante bibliografia a respeito (Donnangelo, 1975, 1976; Nogueira, 1977; Mendes-Gonçalves, 1979, 1992, 1994; Almeida e Rocha, 1986; Campos, 1988; Schraiber, 1993), apenas assinalamos alguns conceitos que retomaremos adiante, ao tratarmos das mudanças em curso nos processos de trabalho em saúde.

\section{As mudanças no processo de trabalho em saúde}

O impacto que o novo contexto de produção globalizada centrado no processo produtivo flexível provoca no trabalho em saúde ainda precisa ser mais bem compreendido, mas certamente há repercussões, algumas mais explícitas, como as que decorrem das mudanças organizacionais e gerenciais e das inovações tecnológicas, ambas incorporadas pelos serviços de saúde.

Dadas as características de setor terciário e as peculiaridades do objeto de trabalho - as necessidades de saúde, sentidas e trazidas aos serviços pelos sujeitos/usuários e apreendidas e interpretadas tecnicamente pelos sujeitos/ agentes do trabalho - o trabalho em saúde configura-se como trabalho reflexivo, destinado à prevenção, manutenção ou restauração de “algo" (a saúde) imprescindível ao conjunto da sociedade.

Chama a atenção a proximidade de algumas características do trabalho em saúde e das mudanças referidas ao novo modo de operar o trabalho na sociedade contemporânea. A nosso ver, tais semelhanças dão-se pela configuração do primeiro como trabalho reflexivo, e pela atual tendência à maior intelectualização do trabalho em geral, sobretudo pela incorporação da microeletrônica e da informática. Salientamos, portanto, a natureza peculiar do trabalho em saúde e a forma particular como desenvolveram-se os estudos nesse campo, atribuindo relevância à dimensão do saber.

Como trabalho reflexivo, o trabalho no setor saúde é dotado de incertezas e descontinuidade, o que acarreta a impossibilidade de normatizar completamente e a priori as funções técnicas e, também, de definir rígidos critérios econômicos de produção. Apesar destas características, o trabalho em saúde, assim como o trabalho industrial, tem sido gerenciado, predominantemente, nos moldes tayloristas e fordistas, o que implica constantes embates entre as variadas autonomias profissionais e os constrangimentos organizacionais. 
Apesar da gerência marcadamente taylorista, observamos, no Brasil, desde a década de 80, influências do planejamento estratégico e do gerenciamento flexível participativo nos serviços de saúde, assim como de projetos de controle de qualidade em saúde.

Estas novas formas organizacionais/gerenciais, junto à promoção da garantia de qualidades dos serviços, acrescidas da necessidade e cobrança de maior produtividade, da crescente incorporação de tecnologia, da constante inovação tecnológica, e da complexidade do objeto de trabalho que requer simultaneamente o aprofundamento vertical do conhecimento especializado e a sua integração, vêm acarretando mudanças no processo de trabalho em saúde. Tais alterações que repercutem na prática cotidiana dos profissionais, colocando-os em situações que requerem articular as intervenções e atividades realizadas pelo profissional com as ações dos demais agentes da equipe, destacando o caráter multiprofissional da prática; redimensionar a autonomia profissional, ou seja, o alcance da liberdade de decisão e conduta de cada agente, autonomia esta que se encontra fortemente tensionada pela necessidade de recomposição dos inúmeros trabalhos parcelares e de comunicação entre os agentes especializados; articular conhecimentos oriundos de várias disciplinas ou ciências, destacando o caráter interdisciplinar da prática; e maior qualificação profissional, tanto na dimensão técnica especializada, quanto na dimensão ético-política, comunicacional e inter-relacional.

O primeiro aspecto assinalado refere-se ao caráter multiprofissional das práticas.

Schraiber e Mendes-Gonçalves (1994) e Pires (1996), ao tratarem dos impactos das inovações tecnológicas na assistência em saúde, destacam o incremento do processo de divisão do trabalho médico e a institucionalização dos serviços.

A divisão do trabalho é processual e complexa, pois cada trabalho que se individualiza assim o faz pela necessidade histórica de sua peculiar atuação especializada, configurando saberes e ações que lhe são próprios e singulares. Reflete, desta maneira, não apenas o desenvolvimento científico tecnológico, mas a própria dinâmica social das práticas de saúde, e não apenas a divisão técnica e pormenorizada de trabalhos, mas a desigual valoração social destes.

Referimo-nos, indistintamente, à divisão do trabalho em saúde e à divisão do trabalho médico, pois a prática dos médicos é a fundadora da técnica científica moderna na área da saúde e o núcleo original do qual outros trabalhos derivam. Assim, a divisão do trabalho caracteriza-se pelo processo de divisão interna do trabalho médico constituindo as especialidades médicas, pelo desdobramento do trabalho médico em atividades assumidas por outros agentes, tais como a enfermagem, e pela agregação de outros profissio- 
nais com áreas de atuação complementares, como psicologia, serviço social e tantos outros (Mendes-Gonçalves, 1992).

Esses trabalhos que decorrem ou agregam-se ao trabalho médico configuram um conjunto diversificado de profissionais, necessário à implementação da totalidade das ações que viabilizam a atenção integral almejada na prestação de serviços de saúde, na atualidade. A divisão do trabalho permite o significativo aumento da produtividade dos serviços e o aprofundamento qualitativo dos cuidados especializados, todavia, acarreta uma fragmentação de ações que, por sua vez, apresenta desafios no sentido de alcançar alguma recomposição.

Esse processo de coletivização do trabalho dá-se simultaneamente ao que se convencionou denominar de movimento de institucionalização da saúde. Neste, as formas de organização de práticas mais ou menos espontâneas, informais ou alternativas, como também as práticas liberais na acepção estrita do termo, tendem, se não ao desaparecimento progressivo, a pelo menos uma subordinação crescente às forças de trabalho institucional (Machado et al., 1992). A institucionalização dos serviços, que é sobretudo produto da incorporação de tecnologia médica, também acarreta situações de trabalho estritamente coletivo.

Temos, então, que a eficácia da produção dos serviços resulta da composição e cooperação do trabalho de distintos profissionais, da complementaridade e interdependência das suas ações. Porém, o trabalho coletivo pode configurar-se segundo diferentes formas de interdependência, apresentando vários tipos de conexões entre os trabalhos parcelares, que podem, inclusive, não estar aparentes para os profissionais, de modo a apreenderem os distintos trabalhos como meras justaposições. A noção de equipe de saúde, por sua vez, no nosso entender, refere-se, não à justaposição, mas à articulação e integração de diferentes processos de trabalho, pois cada trabalho parcelar ou especializado constitui um processo peculiar, com objetivos, saberes e instrumentos próprios (Peduzzi e Palma, 1996; Peduzzi, 1998)².

Na divisão do trabalho, as diferentes autoridades técnicas transmutamse em trabalhos desiguais para além de diversos, onde há valores hierarquizando e disciplinando as diferenças, e os próprios profissionais/agentes dos trabalhos são reconhecidos como sujeitos desiguais. No entanto, a articulação almejada e necessária para a integralidade das ações de saúde pressupõe a atuação consciente de sujeitos dispostos à integração. Esta não ocorre automaticamente na sucessão de atividades e intervenções produzidas pelos vários profissionais, mas depende de conexões percebidas e introduzidas ativa e conscientemente pelos sujeitos do trabalho.

Vários autores propõem a constituição de equipes de saúde no plano micro-institucional para viabilizar a integração da assistência; quebrar a costumeira divisão do trabalho segundo recortes verticais em segmentos estan- 
ques de categorias profissionais; superar a inércia e a indiferença burocrática; reconstituir a unidade perdida do trabalho social cujo objetivo é a atenção de saúde; e democratizar o contexto intra-organizacional (Campos, 1992; Mendes et al., 1994; Testa, 1995; Peduzzi e Palma, 1996).

O trabalho em equipe não implica eliminar as diferenças que são, segundo Testa (1995), possivelmente necessárias e convenientes, mas que podem ser utilizadas como instrumento no avanço da democratização e da ética nas relações de trabalho e no próprio trabalho produzido. Trata-se, então, de enfrentar as diferenças, onde uns sabem mais que outros e, sobretudo, sabem coisas distintas, nos aspectos em que elas traduzem desigualdades sociais.

Seria conveniente investir no diálogo, discutindo as intervenções técnicas, seus antecedentes e suas conseqüências, não somente entre os pares, mas também entre as diferentes áreas profissionais. "A dimensão comunicativa compõe a prática técnica e as vantagens das discussões em equipe de trabalho residem no fato de que se devem compatibilizar todos os procedimentos a serem aplicados (...) é preciso garantir todos e cada um dos passos prévios e sucessivos à intervenção, incluindo, os mais ínfimos detalhes administrativos (as provisões) e de cuidados (a higiene de todos os ambientes) e essa garantia será maior à medida que os membros da equipe saibam porque se requer deles o que se requer" (Testa, 1995,p.296).

Nesse diálogo sobre a complementaridade e interdependência dos trabalhos, estão incluídas a dimensão técnica, referida às atividades, aos procedimentos e a todos os instrumentos necessários para atingir a finalidade de prestação de cuidados, e a dimensão ética, que não se reduz ao relacionamento interpessoal entre os profissionais, que se espera ser respeitoso como cabe ser nas relações humanas, mas estende-se à preocupação em reconhecer e considerar o trabalho dos demais, sejam da mesma área de atuação, sejam de outras.

A construção do trabalho em equipe requer, portanto, também a explicitação e o enfrentamento dialógico de conflitos, buscando uma dinâmica de flexibilidade de regras, negociações e acordos entre agentes, e requer compartilhar decisões e responsabilidades.

O trabalho em equipe, que tem sido defendido como um aspecto relevante nas mudanças do atual processo produtivo flexível, representa uma proposta assinalada há décadas no campo da saúde, ou seja, desde os anos 50, na área da saúde em geral, e desde os anos 30, na área de saúde mental. No Brasil, as equipes de saúde vêm sendo enfatizadas e problematizadas como uma importante questão para o setor saúde, sobretudo a partir dos anos 70, com a introdução das propostas da medicina comunitária e preventiva.

As mudanças do mundo do trabalho industrial, como vimos, falam de uma tendência à atenuação da divisão do trabalho, porém, em saúde, os estudos mostram que a incorporação de tecnologia intensificou a divisão do 
trabalho e a tendência está na valorização do trabalho em equipes multiprofissionais mais qualificadas, dada a absorção de profissionais universitários não médicos e de auxiliares de enfermagem, no lugar da bipolaridade médico-atendente predominante até meados dos anos 80 (Machado et al., 1992).

O trabalho em saúde, conforme caracterizado até o momento, requer autonomias relativas dos profissionais. A autonomia profissional é tradicionalmente reconhecida como um atributo do trabalho médico, uma vez que as ações diagnósticas e terapêuticas constituem trabalho técnico com forte base intelectual e subjetiva, que implicam em julgamentos e opções que permitem traduções e mediações entre a normatividade biológica e a normatividade social (Schraiber, 1993). E, na medida em que, na intervenção em saúde, nada é totalmente definitivo antes da execução, isto é, não é possível desenhar um projeto assistencial que já seja definitivo e único antes de sua implementação, graus variáveis de autonomia ocorrem para o amplo leque de profissionais médicos e não-médicos e, principalmente, definem-se no jogo da equipe de trabalho. Vale ressaltar que esta variabilidade dirá respeito a uma maior ou menor autoridade técnica, socialmente legitimada e não apenas tecnicamente estabelecida, das distintas áreas profissionais e distintas especialidades médicas.

Temos, portanto, no trabalho em saúde, simultaneamente, a necessidade de autonomia técnica e a necessidade de cooperação e composição dos trabalhos especializados. Assim, a autonomia técnica é tensionada, pois, por um lado, o profissional especializado não pode prescindir de um certo espaço de liberdade para a tomada de decisão e isolamento para sua implementação e, por outro lado, justo por ser especializado, não domina a integralidade do projeto de trabalho (assistencial, de produção tecnológica ou de pesquisa), não podendo prescindir da complementaridade objetiva de ações e atividades planejadas e executadas por outros profissionais.

Este tensionamento enfrenta também as peculiaridades de linguagem de cada especialidade, muitas vezes parecendo herméticas aos não-iniciados e dificultando a comunicação e inter-relação imprescindíveis à cooperação. Trata-se de um exercício de mão dupla, em que o profissional precisa saber exercer um certo grau de autonomia e responsabilizar-se plenamente pela sua intervenção e, simultaneamente, articular suas ações e interagir com os demais trabalhos.

Quanto ao terceiro aspecto, vale ressaltar que a interdisciplinaridade não é um projeto novo, se considerarmos a existência de um saber unitário desde os mestres gregos e das várias tentativas de integração do saber ao longo da história até o advento da Idade Moderna, no decorrer da qual consolida-se, então, um processo de fragmentação e de desintegração crescente da unidade do conhecimento (Japiassu, 1976; Siebeneichler, 1989).

Assim, o processo de reflexão e prática acerca da interdisciplinaridade é retomado no interior das universidades e demais centros de produção do co- 
nhecimento, a partir de meados do século XX, e, segundo Japiassu (1976), aparece como instrumento e expressão de uma crítica interna do saber, como alternativa para adequar as atividades de ensino e pesquisa às necessidades sócio-profissionais, bem como de superar o fosso que ainda separa as universidades da sociedade.

Schramm (1994) refere-se à interdisciplinaridade como tentativa de ultrapassar os limites pragmáticos da pluri ou multidiscliplinaridade que, como justaposição de competências específicas e setoriais, nem sempre consegue chegar a um verdadeiro acordo na tomada de decisões e a uma integração dos pontos de vista das partes envolvidas. Assim sendo, define a interdisciplinaridade como método específico de uma co-existência entre especializações e multiplicação pragmática dos pontos de vista pertinentes por um lado, e da inter-relação e integração metodológico-epistemológica do outro, enfim de uma co-existência ativa e de uma inter-solidariedade das diferenças.

Apesar da pertinência e da atualidade destas questões, vários autores são unânimes em considerar que o fenômeno da interdisciplinaridade está longe de ser evidente, tratando-se de um projeto em construção. Alguns autores assinalam sua particular importância para o campo da saúde (Minayo, 1991; Shramm, 1994; Nunes, 1995).

Como referimos, o campo da saúde apresenta uma intensa complexidade dinâmica na medida em que intervém sobre questões atinentes à vida e à morte, recortadas, como objetos de intervenção, como a saúde e a doença no seu âmbito social. Esta complexidade requer, cada vez mais, uma abordagem interdisciplinar, seja na pesquisa, no ensino, na produção tecnológica, na prestação de serviços. Porém, nestes diferentes âmbitos, a interdisciplinaridade processa-se de forma distinta, pois a coordenação e colaboração das várias ciências ou disciplinas ocorrem, principalmente, no ensino e na pesquisa, estando nas demais esferas, sobretudo no plano do trabalho, mediatizadas pelo saber operante e pelos distintos exercícios profissionais, ou seja, pela multiprofissionalidade.

Estamos, portanto, propondo uma distinção clara entre os planos da interdisciplinaridade e da multiprofissionalidade. O primeiro, referindo-se à integração das várias ciências e disciplinas, tendo um caráter eminentemente epistemológico e filosófico, apesar de fazer-se presente também no trabalho, uma vez que engloba saberes fundados cientificamente ou saberes constituídos eles próprios por diversas disciplinas científicas. Já o segundo se refere à integração das distintas categorias profissionais na operação concreta do trabalho. Ou seja, propomos uma distinção entre os dois planos, assim como propusemos uma diferenciação entre ciência e trabalho, alertando para uma freqüente sobreposição de todas estas dimensões no campo da saúde que está, de fato, inserido no processo produtivo, porém com a importante 
peculiaridade de constituir-se numa ação social fundamentada e criadora de conhecimentos, inclusive, mas não somente, científicos.

Como dizíamos, há mediações entre a ciência e o trabalho e estas importam particularmente, uma vez que estamos refletindo sobre a qualificação do trabalhador de nível médio no interior de uma proposta que busca a articulação trabalho-educação, tendo como ponto de partida o processo de trabalho. Diríamos que os conhecimentos científicos são decodificados e/ou transformados em técnicas e tecnologias, essas sim, diretamente aplicadas nos processos de trabalho. E que, além da técnica, há uma outra forma de mediação entre a ciência e a ação/intervenção, que é o saber operante, ou seja, o que vai ser feito concretamente diante do problema social ou da necessidade apresentada, o domínio do projeto do conjunto de ações necessárias para atender uma dada situação (Schraiber, 1996).

Temos, portanto, dois planos de mediações que serão realizadas pelos profissionais no trabalho em saúde. Por um lado, as mediações entre as disciplinas, pois faz-se cada vez mais necessário articular as várias ciências fundantes da ação, integrando, no interior do saber operante, o caráter interdisciplinar do conhecimento contemporâneo. Por outro, as mediações no plano do trabalho propriamente dito, onde, através dos saberes operantes, os agentes articulam instrumentos e atividades na transformação do objeto de intervenção.

Finalizando, faremos mais algumas considerações sobre o impacto da incorporação tecnológica no emprego e na qualificação profissional em saúde.

Segundo Pires (1996), a utilização de novas tecnologias de base microeletrônica no setor saúde dá-se a partir dos anos 80, e mais intensamente, nos anos 90. Alguns equipamentos tornam-se mais precisos e eficientes e outros tiveram sua utilização ampliada, como por exemplo, os computadores. Interessante observar que os dados gerais sobre emprego em saúde (Machado et al, 1992; Girardi, 1995) e a pesquisa da própria autora (Pires, 1996) mostram que o uso de tecnologia avançada não teve como conseqüência, até hoje, a diminuição dos postos de trabalho. No entanto, o estudo de Girardi (1995), em particular, alerta para uma desaceleração sustentada nos ritmos de crescimento da ocupação geral em saúde no decorrer dos últimos 20 anos, sem relacionar este comportamento à tecnologia médica.

Essa situação difere da encontrada nas empresas de produção material, em que a automação e o processo de reestruturação têm diminuído significativamente a incorporação de trabalhadores e causado crescente desemprego.

No que se refere à área da saúde, é importante lembrarmos que a incorporação desta tecnologia avançada ocorre de forma desigual. Acontece principalmente nas instituições públicas e privadas de médio e grande porte, consideradas como 'de ponta' no setor (Pires, 1996).

Lembramos que o uso de tecnologia 'de ponta' exige uma melhor qualificação do trabalhador para manuseio dos equipamentos, ao mesmo tempo 
que aprofunda uma cisão entre trabalhadores mais qualificados (na assistência direta, nos serviços de apoio diagnóstico e terapêutico, na gerência e na produção de tecnologia) e trabalhadores terceirizados e em situações de contrato precário. Este aspecto, sim, em tudo semelhante ao que vem ocorrendo com as mudanças do mundo do trabalho em geral.

\section{Notas}

1 Doutora em Saúde Coletiva pela Faculdade de Ciências Médicas da Universidade Estadual de Campinas. Docente do Departamento de Orientação Profissional da Escola de Enfermagem da Universidade de São Paulo. <marinape@usp.br>

2 A autora desenvolveu a pesquisa de doutorado sobre a temática trabalho em equipe, particularmente sobre equipe multiprofissional de saúde.

\section{Referências}

ALMEIDA, Maria Cecília P.; ROCHA, Juan S. Y. 1986. O saber da enfermagem e sua dimensão prática. São Paulo: Cortez.

ANTUNES, Ricardo. 1995. Adeus ao trabalho? Ensaio sobre as metamorfoses e a centralidade do mundo do trabalho. São Paulo: Cortez/Unicamp.

BERNARDES, Roberto. 1994. Trabalho: a centralidade de uma categoria analítica. São Paulo em Perspectiva, 8(4): 33-41.

CAMPOS, Gastão W. S. 1988. Os médicos e a política de saúde. São Paulo: Hucitec.

_. 1992. Sobre a reforma da reforma: repensando o SUS. In: Reforma da reforma: repensando a saúde (Campos, G. W. S. org.) pp. 133-134, São Paulo: Hucitec. DONNANGELO, Maria Cecília. F. 1975. Medicina e sociedade. São Paulo: Pioneira. . PEREIRA, Luiz. 1976. Saúde e sociedade. 2a ed. São Paulo: Duas Cidades.

FOUCAULT, Michel. 1995. A arqueologia do saber. 4a ed. Rio de Janeiro: Forense Universitária.
GIRARDI, Sabado N. 1995. A situação atual dos recursos humanos em saúde no Brasil. Belo Horizonte, mimeo.

GITAHY, Leda. 1994. Inovação tecnológica, subcontratação e mercado de trabalho. São Paulo em Perspectiva, 8(4): 144-153.

HABERMAS, Jürgen. 2001. Teoría de la acción comunicativa. Madrid: Taurus. Vol. 1 e 2 .

IANNI, Otavio. 1994. O mundo do trabalho. São Paulo em Perspectiva, 8(4): 2-12.

JAPIASSU, Hilton. 1976. Interdisciplinaridade e patologia do saber. Rio de Janeiro: Imago.

MACHADO, Maria Helena et al. 1992. O mercado de trabalho em saúde no Brasil: estrutura e conjuntura. Rio de Janeiro: Ensp/Fiocruz.

MENDES, Eugênio V. et al. 1994. Distritos sanitários: conceitos-chaves. In: Distritos sanitários: o processo social de mudança das práticas do Sistema Único de Saúde (Mendes, E. V., org.) pp. 159-185. 
2a ed., São Paulo - Rio de Janeiro: Hucitec-Abrasco.

MENDES-GONÇALVES, Ricardo Bruno. 1979. Medicina e história: raízes sociais do trabalho do médico. Dissertação de Mestrado, São Paulo: Faculdade de Medicina, Universidade de São Paulo.

1994. Tecnologia e organização social das práticas de saúde. São Paulo: Hucitec-Abrasco.

1992. Práticas de saúde: processos de trabalho e necessidades. Centro de Formação dos Trabalhadores em Saúde as Secretaria Municipal da Saúde, Cadernos CEFOR, 1 - Série Textos, São Paulo.

MINAYO, Maria Cecília S. 1991. Interdisciplinaridade: uma questão que atravessa o saber, o poder e o mundo vivido. $M e$ dicina, Ribeirão Preto, 24(2): 70-77.

NOGUEIRA, Roberto P. 1977. Medicina interna e cirurgia: a formação social da prática médica. Dissertação de Mestrado, Rio de Janeiro: Instituto de Medicina Social, Universidade Estadual do Rio de Janeiro.

NUNES, Everardo D. 1995. A questão da interdisciplinaridade no estudo da saúde coletiva e o papel das ciências sociais. In: Dilemas e desafios das ciências sociais na saúde coletiva (Canesqui, A. M., org), São Paulo/Rio de Janeiro: Hucitec/ Abrasco.

OFFE, Claus. 1989. Trabalho e sociedade: problemas estruturais e perspectivas para o futuro da sociedade do trabalho. Vol I, Rio de Janeiro: Tempo Brasileiro.

PEDDUZZI, Marina; PALMA, J. J. L. 1996. A equipe de saúde. In: Saúde do adulto: programa e ações na unidade básica. (Schraiber, L. B.; Nunes, M. I. B.; Mendes-Gonçalves, R. B. org) São Paulo: Hucitec, pp.234-250,.

PEDUZZI, Marina. 1998. Equipe multiprofissional de saúde: a interface entre trabalho e interação. Tese de Doutorado, Campinas: Faculdade de Ciências Médicas, Universidade Estadual de Campinas (SP).

PIRES, Denise. 1996. Processo de trabalho em saúde no Brasil no contexto das transfor- mações atuais na esfera do trabalho: estudo em instituições escolhidas. Tese de Doutorado, Campinas: Instituto de Filosofia e Ciências Humanas, Universidade Estadual de Campinas (SP).

RIBEIRO, José M.; SCHRAIBER, Lilia. 1994. B. A autonomia e o trabalho em medicina. Cadernos de Saúde Pública, 10(20); 190-199.

SCHRAIBER, Lilia B. 1993. O médico e seu trabalho: limites da liberdade. São Paulo: Hucitec.

SCHRAIBER, Lilia B. 1995. O trabalho médico: questões da autonomia profissional. Cadernos de Saúde Pública, 11(1): 57-64.

SCHRAIBER, Lilia B. 1996. Ciência, trabalho e trabalhador de saúde: contribuições de Ricardo Bruno Mendes-Gonçalves para a compreensão da articulação entre saber, prática e recursos humanos. $D i$ vulgação em Saúde para Debate, n. 14.

SCHRAIBER, Lilia B.; MENDES-GONÇALVES, Ricardo B. 1994. El reto de la educación médica frente a los nuevos paradigmas económicos y tecnológicos. Educacion Medica y Salud, 28(1): 20-52.

SCHRAIBER, Lilia B.; PEDUZZI, Marina. 1993. Tendências e possibilidades da investigação de recursos humanos em saúde no Brasil. Educacion Medica y Salud, 27(3): 295-313.

SCHRAMM, Fermin R. 1994. A ética natural. Texto apresentado em aula ministrada no Departamento de Medicina Preventiva e Social da Faculdade de Medicina da Universidade Estadual de Campinas, Campinas. (Mimeo.)

SIEBERNEICHLER, Flavio B. 1989. Encontros e desencontros no caminho da interdisciplinaridade: G. Gusdorf e J. Habermas. Revista Tempo Brasileiro, Rio de Janeiro, 98: 153-180, jul-set/89.

TESTA, Mário. Estratégia e programação. 1995. In: Pensamento estratégico e lógica de programação: o caso da saúde (Testa, M.org.) pp. 201-306, São Paulo-Rio de Janeiro: Hucitec. 